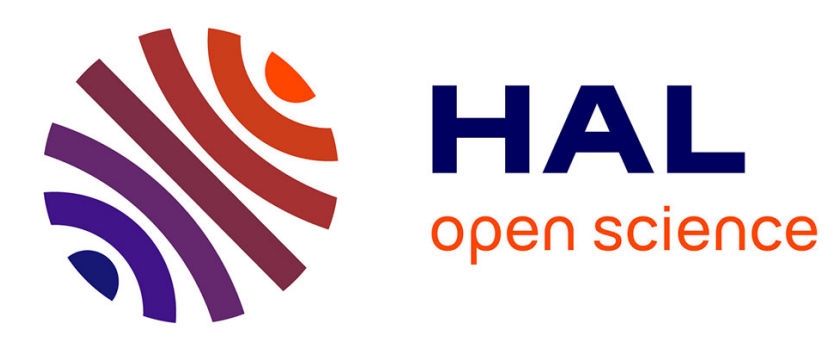

\title{
Anomalous Behaviour of the Zener Relaxation in $\mathrm{Cu}-\mathrm{Au}$
} F. Povolo, E. Hermida

\section{- To cite this version:}

F. Povolo, E. Hermida. Anomalous Behaviour of the Zener Relaxation in Cu-Au. Journal de Physique IV Proceedings, 1996, 06 (C8), pp.C8-85-C8-88. 10.1051/jp4:1996816 . jpa-00254594

\section{HAL Id: jpa-00254594 https://hal.science/jpa-00254594}

Submitted on 1 Jan 1996

HAL is a multi-disciplinary open access archive for the deposit and dissemination of scientific research documents, whether they are published or not. The documents may come from teaching and research institutions in France or abroad, or from public or private research centers.
L'archive ouverte pluridisciplinaire HAL, est destinée au dépôt et à la diffusion de documents scientifiques de niveau recherche, publiés ou non, émanant des établissements d'enseignement et de recherche français ou étrangers, des laboratoires publics ou privés. 


\title{
Anomalous Behaviour of the Zener Relaxation in $\mathrm{Cu}-\mathrm{Au}$
}

\author{
F. Povolo and E.B. Hermida \\ Departamento de Física, Fac. de Ciencias Exactas y Naturales, Universidad de Buenos Aires, Pabellón I, \\ Ciudad Universitaria, 1428 Buenos Aires, Argentina \\ Unidad de Actividad Materiales, Comisión Nacional de Energía Atómica, Av. del Libertador 8250, \\ 1429 Buenos Aires, Argentina \\ Consejo Nacional de Investigaciones Científicas y Técnicas (CONICET), Buenos Aires, Argentina
}

\begin{abstract}
Measurements of the Zener relaxation in single crystals of $\mathrm{Cu}-18 \mathrm{at} . \% \mathrm{Au}$ and $\mathrm{Cu}_{3} \mathrm{Au}$ are presented. In the 18at.\% alloy only one internal friction peak is observed at low frequencies (of the order of $1 \mathrm{~Hz}$ ). This peak is only slightly wider than a Debye's peak. An additional hump appears at intermediate frequencies (of the order of $60 \mathrm{~Hz}$ ). The Zener peak in the $\mathrm{Cu}_{3} \mathrm{Au}$ alloy is accompanied by an additional maximum produced by the order-disorder transition.

A measurement of the derivative of the damping with respect to the frequency through the use of a pendulum with variable moment of inertia shows that non-linear effects are present in the Zener relaxation in both alloys.
\end{abstract}

\section{INTRODUCTION}

The Zener peak is due to stress-induced ordering which occurs in substitutional solid solutions. A survey of this relaxation process has been made recently [1]. Data on the Zener relaxation in the $\mathrm{Cu}$-Au system in single and polycrystals have been reported [2,3]. The analysis of these experimental data, however, was mainly based on linear viscoelasticity and no amplitude-dependent effects were considered. Furthermore, the Zener peaks are normally assumed to be amplitude independent.

It is the purpose of this paper to analyze the frequency dependence of the Zener relaxation in two $\mathrm{Cu}-18 \mathrm{at} . \% \mathrm{Au}$ and $\mathrm{Cu}_{3} \mathrm{Au}$ single crystals, showing that they manifest non-linear effects.

\section{THEORETICAL BACKGROUND}

The internal friction $F$ of any viscoelastic material can be expressed as [4]

$$
F(\omega, T)=\frac{1}{2} \int_{-\infty}^{\infty} \frac{\Phi_{t}(\tau, T)}{\cosh [\ln (\omega \tau)]} \mathrm{d}(\ln \tau)
$$

where $\tau$ is the relaxation time, $\Phi_{t}$ the tangent distribution function, $\omega$ the angular frequency of the applied stress and $T$ the absolute temperature. If eq. (1) is fulfilled, then [5]

$$
\left|\frac{\partial \ln F}{\partial \ln \omega}\right|_{T} \mid \leq 1
$$

This condition is necessary for a process to be linear but is not enough to establish the linearity of a damping behaviour. In other words, non-linear processes may satisfy eq. (2) but, if this condition is not obeyed, the presence of non-linear mechanisms in the relaxation can be assured. 


\section{EXPERIMENTAL PROCEDURE}

The Zener relaxation was measured as a function of temperature in high vacuum using a modified traditional torsion pendulum [6]. This allows to keep the frequency constant in the whole temperature range of the damping peak, due to the slightly variable moment of inertia. In this way not only the traditional curves of $F$ and $\omega$ but also that of $F_{c}$-internal friction at a constant frequency $\omega_{c}-$ are determined as a function of temperature. Then, the slight changes of $\omega$ with temperature justifies the following approximation

$$
\left.\left.\frac{\partial \ln F}{\partial \ln \omega}\right|_{T} \approx \frac{\ln \left(F_{c} / F\right)}{\ln \left(\omega_{c} / \omega\right)}\right|_{T}
$$

Thus, the data obtained with the pendulum with variable moment of inertia are used to determine whether non-linear processes are involved.

Two different types of single crystal wires were employed: $\mathrm{Cu}-18 \mathrm{at} . \% \mathrm{Au}$ and $\mathrm{Cu}_{3} \mathrm{Au}$. The experimental procedure to obtain the single crystal specimens is described elsewhere [2]. The internal friction measurements were made on heating at approximately $60 \mathrm{~K} / \mathrm{h}$ both at low and intermediate frequencies. The orientation factors of the two crystals were of the order of $\Gamma=1 / 3$.

\section{RESULTS}

Fig. 1 shows the data obtained in $\mathrm{Cu}-18 \mathrm{at} . \% \mathrm{Au}$ at low frequencies after subtracting out a small background. The frequency at the maximum is $\omega_{m} \approx 52.3 \mathrm{~s}^{-1} . \quad \partial \ln F /\left.\partial \ln \omega\right|_{T}$ obtained by using eq. (3) is also indicated. Fig. 2 shows the results obtained in another part of the same single crystal at low and intermediate frequencies. $\omega_{m}$ is indicated in the same figure. It can be observed that a hump, which appears at intermediate frequencies, is not present in Figs. 1 and 2 at low frequencies.

Fig. 3 shows the data obtained in a $\mathrm{Cu}_{3} \mathrm{Au}$ single crystal at intermediate frequencies, together with $\partial \ln F /\left.\partial \ln \omega\right|_{T}$. An additional small peak, produced by the order-disorder transition, can be observed at lower temperatures. Finally, the results obtained in the same specimen at low and intermediate frequencies are compared in Fig. 4.

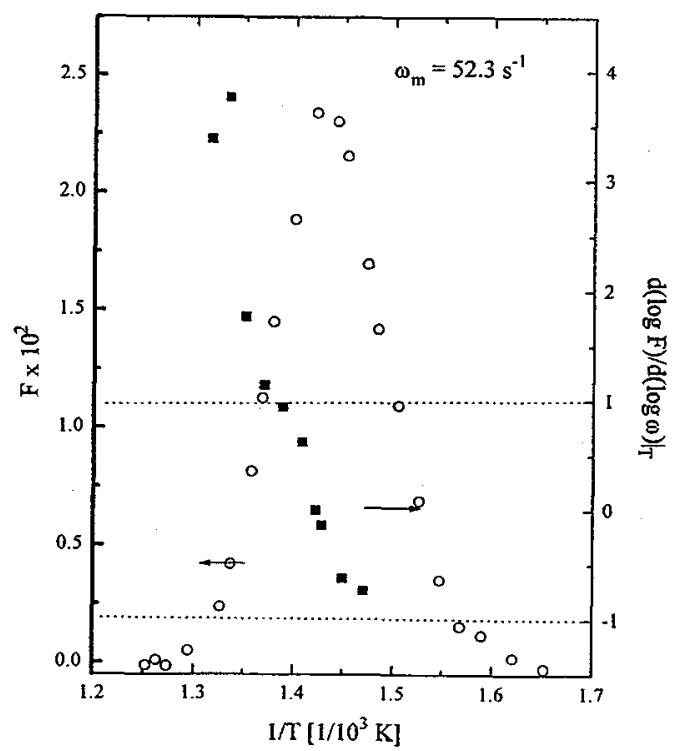

Fig. 1: Zener peak and its derivative for $\mathrm{Cu}-18 \mathrm{at} \% \mathrm{Au}$.

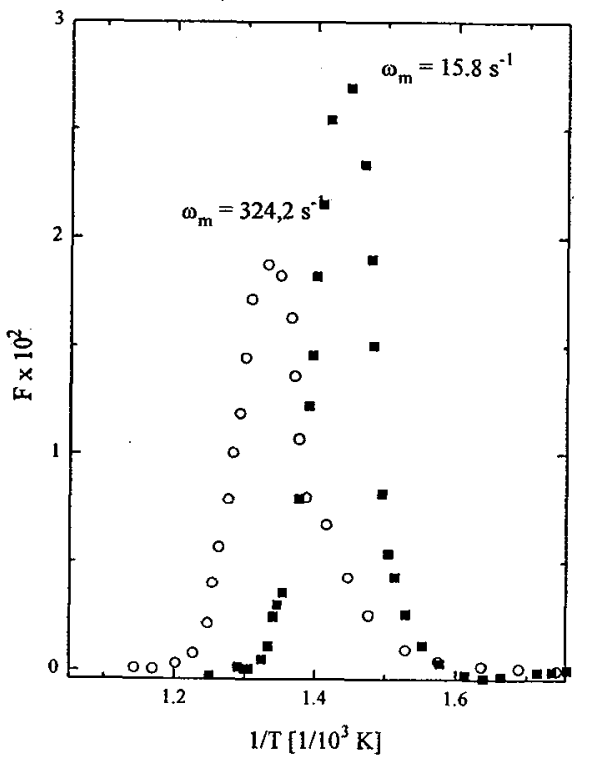

Fig. 2: Zener peaks in $\mathrm{Cu}-18 \mathrm{at} \% \mathrm{Au}$ at two frequencies. 


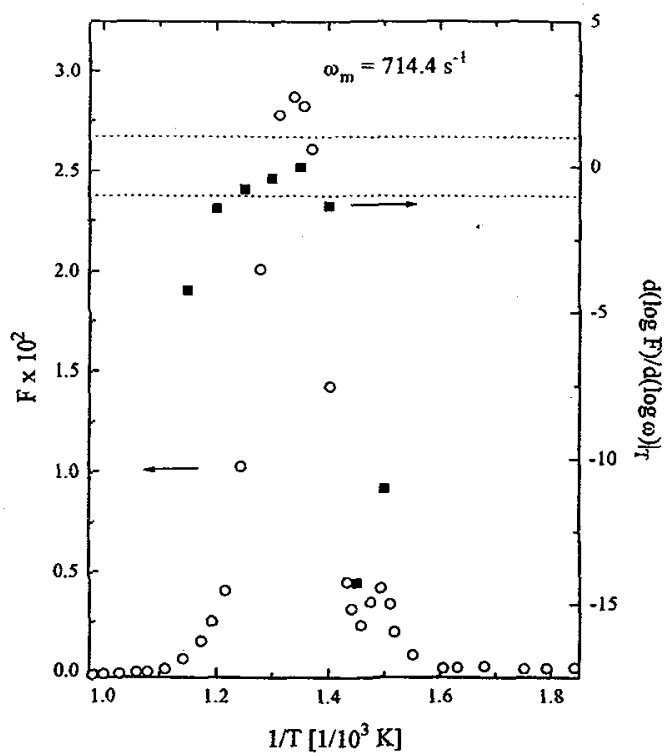

Fig. 3: Zener peak and its derivative for $\mathrm{Cu}_{3} \mathrm{Au}$.

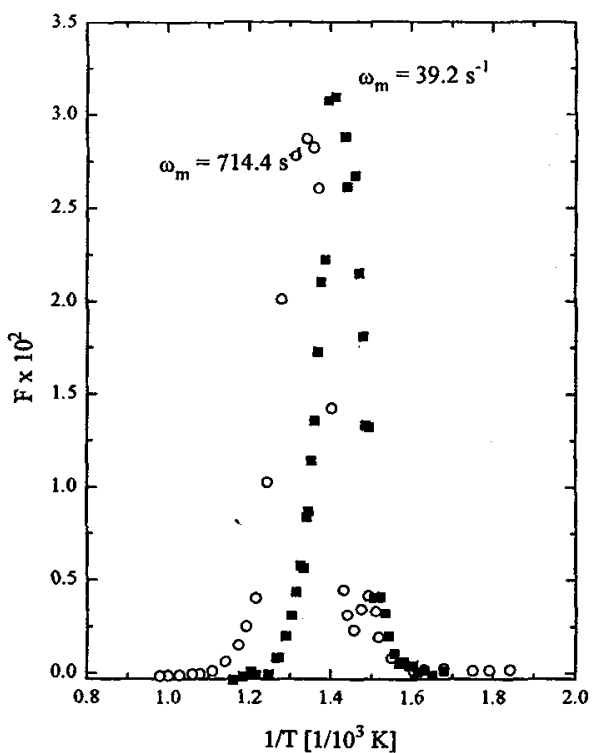

Fig. 4: Zener peaks in $\mathrm{Cu}_{3} \mathrm{Au}$ at two frequencies.

\section{DISCUSSION}

It is clearly seen from Figs. 1 and 3 that the condition given by eq. (2) is not satisfied neither in Cu-18at.\% Au nor in $\mathrm{Cu}_{3} \mathrm{Au}$. This condition is not fulfilled even far from the tails of the peaks where no so large errors are involved in the calculation of $\partial \ln F /\left.\partial \ln \omega\right|_{T}$ by eq. (3). In effect, it should be taken into account that a backgroung has been subtracted out from the peaks of Figs. 1 to 4 introducing large errors in the determination of the tails, particularly at high temperatures. From the phase diagram, it is well-known that an order-disorder transition in $\mathrm{Cu}_{3} \mathrm{Au}$ occurs at $663 \mathrm{~K}$ [7]. This transition is shown clearly by the small peak at low temperatures of Fig. 3. It is also illustrated in the same figure how $|\partial \ln F / \partial \ln \omega|_{T} \mid>1$ except in a small region near the maximum of the internal friction. This shows that non-linear phenomena are present in the Zener relaxation in $\mathrm{Cu}_{3} \mathrm{Au}$. Finally, Fig. 4 compares the Zener peaks measured at two frequencies. At the lower one the internal friction peak produced by the order-disorder transition is masked by the Zener relaxation. Furthermore, the Zener peak is higher as the temperature of the maximum approaches the order-disorder transition, as it is shown on comparing the peaks measured at low and intermediate frequencies. As shown in Fig. 1, non-linear effects are also present in $\mathrm{Cu}-18 \mathrm{at} . \% \mathrm{Au}$ alloys, $\operatorname{since}|\partial \ln F / \partial \ln \omega|_{T} \mid>1$, except in a region near the maximum of the internal friction peak. As shown in Fig. 2 there is a perturbation in the low temperature tail of the peak measured at $51.6 \mathrm{~s}^{-1}$, which is not present in the same specimen measured at $15.8 \mathrm{~s}^{-1}$, since the small hump is masked by the Zener peak. As for $\mathrm{Cu}_{3} \mathrm{Au}$, the Zener peak increases when the maximum approaches the temperature corresponding to the small hump, that is, when the peak is measured at the lower frequency. In fact, it is generally observed that the temperature dependence of the relaxation strength, $\Delta_{M}$, obeys a Curie-Weiss-type law [1]

$$
\Delta_{M}^{-1} \propto\left[T-T_{M}^{(a n)}\right]
$$

where $T_{M}^{(a n)}$ is the anelastic critical temperature at which ordering would occur spontaneously if 
at.omic movements were possible. This means that the Zener peak should increase as the peak temperature approaches $T_{M}^{(a n)}$. If $T_{M}^{(a n)}$ is of the order of the critical temperature for ordering, as suggested in [3], then the hump in the Cu-18at.\%Au alloy should occur at temperatures lower than for $\mathrm{Cu}_{3} \mathrm{Au}$, because according to the most accepted phase diagram [7] the order-disorder transition in the former occurs at lower temperatures than in the later. In any case, the exact temperature dependence of the relaxation strength can be evaluated only numerically and eq. (4) is only an approximation valid in the high temperature limit [l].

The linear characteristics of the Zener peaks in Cu-18at.\% Au and $\mathrm{Cu}_{3} \mathrm{Au}$ have been discussed in detail elsewhere $[2,3]$. It should be pointed out that the width at half maxiumm of the Zener peaks shown in Figs. 1 to 4 are close to those predicted for Debye peaks, on using the activation enthalpies measured by the shifts of the maxima with frequency. However, $\partial \ln F /\left.\partial \ln \omega\right|_{T}$ shows clearly that non-linear phenomena are involved. In any case, more work is needed to establish the mechanisms which produce the non-linear effects and the hump observed in the peak measured at intermediate frequency in Cu-18at.\% Au.

Finally, it is noticed that non-linear phenomena were determined [5]on calculating the logarithmic derivative of the Zener peak measured as a function of frequency in Ni-25.5at.\% Al at 831, 864 and $883 \mathrm{~K}[8]$.

\section{Acknowledgements}

The authors would like to thank Dr. O. A. Lambri and Mr. F. Saavedra, who measured the Zener peaks shown in this paper.

This work has been supported partially by CONICET, the University of Buenos Aires, the Antorchas Foundation and the Proyecto Multinacional de Investigación y Desarrollo en Materiales OAS-CNEA.

\section{References}

[1] E. Povolo and H. O. Mosca, in Mechanical Spectroscopy, B. M. Magalas, Ed. (Elsevier Applied Science, in press).

[2] F. Povolo and A. F. Armas, Acta metall. 31 '(1983) 643 - 654.

[3] F. Povolo and A. F. Armas, Phil. Mag. A 49 (1984) 865 - 872.

[4] F. Povolo and C. L. Matteo, Mater. Trans., JIM 33 (1992) $824-833$.

[5] Élida B. Hermida and F. Povolo, Phys. Rev. B, to appear.

[6] F. Povolo, B. J. Molinas and O. A. Lambri, Nuovo Cimento D 14 (1992) 279 - 286.

[7] H. Okamoto, T. B. Massalski and D. J. Chakrabarti and D. E. Laughlin, in Phase Diagrams of Binary Copper Alloys, P. R. Subramanian, D. J. Chakrabarti and D. E. Laughlin (ASM International, Material Park OH, 1994) pp. 54 - 73.

[8] K. Chakib, PhD. Thesis, University of Poitiers, France (1992). 